\title{
Sufragantes parroquiales y electores. La apertura relativa del mundo de la política electoral en Antioquia, 1821-1848*
}

Recibido: 19/02/2019 | Revisado: 10/04/2019 | Aceptado: 08/05/2019

DOI: $10.17230 /$ co-herencia.16.31.6

\section{Juan Carlos Vélez-Rendón ${ }^{* *}$}

jcarlos.velez@udea.edu.co

\begin{abstract}
Resumen El artículo trata la participación electoral en Antioquia durante los primeros años de vida republicana, con el fin de establecer el alcance de la apertura política propiciada por la puesta en práctica de la denominada soberanía popular. Se enfoca en los sufragantes parroquiales y en los electores, así como en los debates sobre méritos para acceder a cargos de representación, con el objetivo de mostrar la vigencia de antiguos poderes y valores en un ámbito político inédito creado por la influencia de las ideas republicanas y liberales.
\end{abstract}

\section{Palabras clave:}

Elecciones, sufragantes parroquiales, electores, apertura política, Antioquia.

\section{Parochial voters and electors. The relative openness of the world of electoral politics in Antioquia, 1821-1848}

\begin{abstract}
This paper examines the electoral participation in Antioquia during the first years of republican life, in order to establish the scope of the political openness fostered by the implementation of the so-called popular sovereignty. The main focus of the paper is on parish voters and electors, as well as on the debates on criteria to be met in order to be elected for representative positions, with the aim of showing the validity of ancient powers and values in an unprecedented political sphere driven by the influence of republican and liberal ideas.
\end{abstract}

\section{Keywords:}

Elections, parochial voters, electors, political openness, Antioquia.
El artículo es una versión resumida y actualizada de un capítulo de la tesis doctoral "El establecimiento local del sistema republicano en Colombia. Gobierno, representación política y administración de justicia en la provincia de Antioquia, 1821-1853", presentada en El Colegio de México, en 2011. ** Doctor en Historia por El Colegio de México. Integrante del grupo Hegemonía, Guerras y Conflictos, del Instituto de Estudios Políticos de la Universidad de Antioquia, Medellín, Colombia. ORCID: 0000-0002-4567-889X 
Para diferenciarse del absolutismo real, en el sistema republicano se diseñaron instrumentos electorales que hicieran viables la soberanía popular y la conformación de gobiernos representativos que acreditaran la legitimidad formal del nuevo poder político. Como en la Francia posrevolucionaria, los patriotas criollos en América Latina enfrentaron la dificultad de darle cuerpo a la "voluntad general", problema avocado mediante sistemas electorales que introdujeron el voto restrictivo y las elecciones indirectas, con excepciones en países en donde se optó, temporalmente, por el voto universal y directo.

En esa "hibridación" entre lo antiguo y lo moderno de la política decimonónica, advertida tempranamente por François-Xavier Guerra (2012, pp. 133-134), lo electoral no supuso rupturas o una apertura radical del mundo de la política. Antonio Annino (1995) ha planteado que la alternativa censitaria "constituyó un compromiso entre tradición y cambio" (p. 17), en el sentido en que se establecieron instancias (juntas electorales) que reflejaban antiguas ideas del cuerpo político local y, a la vez, se instauraron prácticas inéditas y se crearon nuevos espacios para ejercer la política (el voto individual y la ciudadanía) (Botana, 1995, pp. 470-472). Idea compartida, posteriormente, por Marta Irurozqui (2005), cuando reconoció que la viabilidad del régimen liberal, en relación con la ciudadanía, fue el "resultado de numerosos esfuerzos y tentativas políticas en cuya articulación resultó fundamental la pervivencia de instituciones anteriores a las independencias" (p. 15).

El principio liberal de la voluntad popular se expresaba por medio de representantes elegidos mediante votación, para conformar el Gobierno y el Congreso. Idealmente, la representación política garantizaría al pueblo su participación en la conformación del gobierno, en la confección de las leyes y en la limitación de toda tendencia a la usurpación del poder político. El ciudadano, es decir, la persona habilitada para el ejercicio formal de la política, sería aquella en la que confluyeran atributos sobre los que también se sustentaba el orden burgués: la propiedad como derecho individual, la libertad a la que esta teóricamente daba origen y la igualdad ante la ley. Quienes no reunían tales atributos quedaban por fuera de la participación en la política formal y de la posibilidad de participar en la conformación del gobierno. En América Latina, según Guerra (1999), la ciudada- 
nía sería "el círculo más restringido dentro de una serie de círculos concéntricos y cada vez más excluyentes" (p. 44).

En Colombia, el relativo auge de estudios electorales ha sido acompañado por el análisis de las sociabilidades (Loaiza, 2011) y por la indagación sobre la participación informal en la política, especialmente de sectores subordinados, que ha venido creciendo y parece haber desplazado el interés por esa participación formal que se da en el ámbito liberal de la representación (Gutiérrez, 2018; Castaño, 2008; Salgado, 2014). Aun así, el estudio del sistema electoral y de los comicios ha permitido el conocimiento de aspectos legales, la identificación de protagonistas de la política nacional después de 1821, la puesta en práctica de procedimientos novedosos en ámbitos social y políticamente tradicionales, conflictos derivados de la competencia electoral después de 1837, la formación de bandos partidistas y la manera como trataron de cooptar o contener la participación electoral de sectores sociales subordinados (Deas, 1993; Safford, 1977; Bushnell, 1998; González, 1997; Posada, 1996; Monsalvo, 2005; Ospina y Marín, 2018).

En algunos trabajos, se ha planteado que las elecciones propiciaron una apertura política para personas que no pertenecían a grupos de poder tradicionales; sin embargo, pocos se han ocupado de la puesta en práctica local del sistema electoral y el reacomodo, también local, de las élites, para apuntalarse políticamente en ese tránsito a la República (Escorcia, 1983, pp. 103-108). Estos estudios han mostrado la mecánica electoral en comicios particulares, las controversias locales y las formas de solucionarlas, la práctica comicial, los resultados electorales en entornos urbanos y rurales, así como las redes de poder que se fueron constituyendo para controlar el voto y los resultados electorales en entornos parroquiales concretos (Monsalvo, 2011; 2012; Monsalvo y Medina, 2017). Una explicación para esta ausencia tiene que ver, posiblemente, con el estado, en los archivos, de la información electoral de la primera mitad del siglo XIX: dispersa, inconstante, inconsistente, incompleta, lo que hace ardua la indagación y sistematización de datos.

Para el caso de Antioquia, se ha demostrado que las élites tradicionales preservaron el control político de la gobernación después de la Independencia (Patiño, 1994, pp. 154-182; Hincapié y Álvarez, 
1998) y se ha planteado que "la política" era "asunto de clases altas, habitualmente, aunque ni siquiera entre éstas despertaba mucho interés" (Melo, 1991, pp. 107-111). Sobre la participación electoral de grupos subordinados, Roger Brew (1984) ha planteado que fueron movilizados desde arriba por oligarquías locales que tenían "por uno u otro medio, apoyo popular" (pp. 28-31); aunque advierte que el electorado local se componía de votantes que no eran fáciles de comprar si se decidían a votar, se suponía "que en las elecciones la gente seguía el ejemplo de sus superiores sociales, si acaso con cierta apatía" (Brew, 1984, p. 44).

Pese a estos planteamientos, no se ha ahondado en las personas que se insertaron en las instancias locales de representación, creadas por el sistema electoral republicano. Tampoco se ha reconocido la forma como se yuxtapusieron antiguos conflictos sobre el honor y el estatus, a la lucha por ejercer influencia política por vía electoral. A continuación, se abordan estos aspectos, en particular las personas que, en ámbitos locales, entraron en la política electoral con la instauración de instituciones republicanas en Antioquia.

Este estudio de caso no tiene intención ni pretensión teórica; busca mostrar cómo se establecieron grupos de poder en instancias novedosas de representación política y deja preguntas abiertas acerca de la manera como elites de sectores rurales buscaron acomodo en esas instancias. En primer lugar, se exponen aspectos del sistema electoral indirecto y restrictivo adoptado para poner en práctica la denominada soberanía popular, se aborda la participación de diversos sectores sociales en los comicios y se trata, someramente, el tema de los sufragantes parroquiales en Antioquia. En segundo lugar, se estudian los electores de cantón, a partir de perfiles individuales y colectivos de las personas que buscaron ejercer influencia política por esta vía, entre 1822 y 1842 . Por último, se describe un debate acerca de los méritos de los aspirantes a cargos de representación electoral.

\section{Ciudadanía restringida: el temor por el "ensanche" de la política electoral hacia los sectores populares}

Para Francisco de Paula Santander (1792-1840), vicepresidente de la República de Colombia en ejercicio presidencial entre 1821 y 1827, el procedimiento electoral suponía una ruptura con el absolutismo 
colonial, pues, como explicó en una de sus primeras proclamas, al concurrir a la formación de las leyes, los colombianos quedaban fuera del alcance del sistema "injusto" del Gobierno español; los hombres libres no conocerían otra "servidumbre" que la debida a la ley; y el Gobierno y el Congreso quedarían en manos de "legítimos representantes" del pueblo que conocían el país, a diferencia de los magistrados "desconocidos, estraños y viciosos" que nombraban desde España (Gaceta de Colombia, 1822b, p. 1).

La Constitución de 1821 proclamó la soberanía de la nación, la división del poder público en los cuerpos legislativo (bicameral), ejecutivo y judicial, la igualdad de los colombianos ante la ley, el carácter representativo del gobierno y la conformación del Congreso mediante elecciones censitarias e indirectas. Además, acordó el funcionamiento de asambleas parroquiales y electorales, fijó la representación según la base demográfica de las distintas unidades político-administrativas, y señaló requisitos, funciones y factores de suspensión de los sufragantes y electores (Pombo y Guerra, 1986, pp. 9-75; González, 1997). El desarrollo legislativo regularizó y formalizó el sistema electoral (Gaceta de Colombia, 1824; 1825c), sobre todo en la proximidad de años electorales $(1824,1832,1836,1841)$, o de convocatoria a asambleas o congresos constituyentes (1827, 1830, 1831), cuando se incrementaba la producción normativa que regulaba la realización de comicios (Gaceta de Colombia, 1827a; 1829a; 1829b; 1831). Las Constituciones de 1832 y $1842-43$ introdujeron cambios electorales que fueron desarrollados legislativamente, por ejemplo, con la Ley Electoral del 24 de mayo de 1834, la cual modificaba el procedimiento electoral y la base de la representación política.

De esta reglamentación es importante resaltar tres aspectos que configuraron el carácter restrictivo y ascendente del sistema electoral. En primer lugar, del derecho a votar se excluyó a la mayor parte de la población; en segundo, el sistema era indirecto: en elecciones de primer grado se escogían sufragantes parroquiales, los cuales elegían electores de cantón, quienes tenían la potestad de hacer lo propio con diputados a cámaras provinciales, representantes, senadores, vicepresidente y presidente (Registraduría Nacional del Estado Civil, s. f.); en tercer lugar, el censo de población sirvió de base para calcular la representación política (Gaceta de Colombia, 1827b, p. 4), es 
decir, para definir el dato "objetivo" de las personas reconocidas para el debate electoral (Registraduría Nacional del Estado Civil, s. f., pp. 139-174).

Tal como expuso Marta Irurozqui (1996) para el caso de Bolivia, el voto calificado expresaba el ideal de república restrictiva de las élites, que buscaban un sufragio realizado con juicio, prudencia y responsabilidad para ejercer la libertad política (pp. 701-702). En el caso colombiano, este ideal quedó consagrado en la Constitución de 1821, que declaró la igualdad de los colombianos ante la ley y excluyó del derecho al voto a menores de veintiún años (salvo que fueran casados), a quienes no tuvieran una propiedad de $\$ 100$ (eliminado en 1832) ni oficio o profesión que garantizara independencia, así como a mujeres, trabajadores y personas dependientes (esclavos, concertados, servidumbre, jornaleros, entre otros). De este modo, las élites criollas constituyeron una estrategia de subordinación social bajo el criterio de que la dependencia económica y la falta de propiedad restringían la libertad de la persona, su autonomía para tomar decisiones políticas y el tiempo para dedicarse a los asuntos de la patria. En general, las élites políticas no tenían interés en promover la participación popular en la política electoral o apoyar una movilización de estos sectores por el derecho al sufragio, y no existen evidencias de que tales sectores la reclamaran abiertamente en Antioquia.

El debate sobre el derecho al voto de los militares muestra que, ni aun en este caso, después de 1821, se contempló la posibilidad de otorgar la ciudadanía a quienes prestaran servicios a la patria, independiente de su condición social y económica. Por ejemplo, para la elección de diputados al Congreso de Cúcuta de 1821, se reconoció este derecho a los soldados, pero la Constitución de ese año y la reglamentación posterior lo condicionaron al cumplimiento de los demás requisitos (Pombo y Guerra, 1986, pp. 263-331), difíciles de acreditar para la mayoría de la tropa y, posiblemente, para parte de la oficialidad. Pese a divergencias de opinión entre Santander, vicepresidente en funciones presidenciales, y militares cercanos al presidente Simón Bolívar, el Congreso de 1827 prohibió el voto a quienes, desde el grado de sargentos hacia abajo, no cumplieran los requisitos de la ley (Bushnell, 1966, pp. 299-300; Gaceta de Colombia, 1825b). El proyecto de Bolívar de "hacer de cada militar un ciudadano pro- 
pietario", mediante la asignación de tierras, fue usado por caudillos y oficiales de más alto rango para hacerse a grandes propiedades y no benefició a la tropa (Lynch, 2006, pp. 210-211).

La posibilidad de elecciones directas también fue rechazada por sectores políticamente influyentes, aunque había grupos liberales que empezaron a reclamarla. Por ejemplo, en 1826, se discutieron los términos para convocar una convención nacional y un sector del Congreso propuso, mediante proyecto de ley, que las municipalidades fueran conformadas por "asambleas primarias" con voto directo, eliminando la función del elector. El poder ejecutivo objetó dicha propuesta porque, por un lado, argumentaba que con "las frecuentes reuniones del pueblo" se "molestaba a cada paso a la nación" y se facilitaban congregaciones que "dejeneran de su instituto y arrancan lagrimas a la sociedad"; por otro lado, porque era "absurdo" dar un origen más popular y directo a las municipalidades que el de "los lejítimos y verdaderos representantes de la nación”, es decir, que resultaba de "cierta repugnancia" que los representantes se eligieran por intermedio de electores, y que los municipales lo fueran inmediata y directamente por el pueblo (Gaceta de Colombia, 1826b, p. 3).

Para el ejecutivo, bajo la influencia de Simón Bolívar, la propuesta daba "un ensanche muy extenso al orijen de las municipalidades", desquiciaba el mecanismo de representación y exponía al país a riesgos que suponía el voto directo. Por esta vía, se abría la posibilidad para que "hombres perversos metidos en las municipalidades", reivindicaran "la pureza" de su origen y sumieran la República en el caos y la anarquía, de tal modo que, por "llevar los principios liberales a los estremos más peligrosos", se expondría la nación a disturbios y confusión (Gaceta de Colombia, 1826b). El ejecutivo propuso a los "exaltados republicanos" en el Congreso que sopesaran los "sacrificios" realizados para mantener la estabilidad política, que estudiaran el carácter y cualidades de los pueblos y que excusaran "la timidez" con que actuaba el Gobierno (Gaceta de Colombia, 1826b); el Congreso aceptó la invitación y rechazó la propuesta.

En situaciones extraordinarias, el "pueblo" siguió siendo invocado como el origen del poder, y se lo convocaba para legitimar la conformación de asambleas y corporaciones en cada proceso electoral, pero siempre representado por asambleas parroquiales, electores 
o padres de familia. Por ejemplo, al promediar 1830, en Bogotá se "disolvió" el Gobierno nacional que encabezaba Domingo Caicedo y se estableció uno provisional a cargo del general Rafael Urdaneta. En Antioquia, el prefecto del departamento, Alejandro Vélez, convocó "al pueblo, único origen lejítimo de donde emana toda autoridad", para que resolviera acerca de si obedecer o no a dicho Gobierno (Gaceta de Colombia, 1830b). El procedimiento establecido seguía siendo indirecto: en proporción a su población, los cantones eligieron diputados y estos, reunidos en asamblea departamental (se habían suspendido temporalmente las provincias), resolvieron reconocer el Gobierno de Urdaneta, lo que motivó la renuncia del prefecto y el rechazo de los notables locales (Gaceta de Colombia, 1830b).

La Constitución de 1832, que consagraba formalmente la desintegración de Colombia, no introdujo cambios sobre el voto y, en lugares como Antioquia, prevalecía una opinión favorable sobre el carácter "benéfico" del voto indirecto para la sociedad. El influyente político Miguel Uribe Restrepo (1792-1842) planteaba, en un discurso con motivo de la instalación de una asamblea de electores, que el "sistema popular representativo" -esa "invención feliz de los tiempos modernos"- era "el más razonable, el más conforme á la naturaleza de las cosas, el mejor calculado para promover la felicidad común, i para fijar sobre bases justas é inalterables el imperio de la libertad" (Constitucional de Antioquia, 1836, p. 1). Este mecanismo -decía-garantizaba que el pueblo granadino se reuniera, no de manera "estrepitosa i tumultuaria para [...] turbar, i confundir, i trastornarlo todo", sino de modo "pacífico i juicioso" para elegir mandatarios (Constitucional de Antioquia, 1836, p. 1). Quienes se opusieron al "ensanchamiento" de la participación política formal a sectores populares reforzaron sus temores y prevenciones al constatar la injerencia que sobre ellos tenía el clero local, como se evidenció, años después, en el levantamiento del sacerdote José María Botero, en 1835.

¿Qué pensaba "el pueblo" o los que decían representarlo sobre las elecciones, sobre el derecho al sufragio o sobre el voto indirecto? A diferencia de otros lugares del país, como Cartagena, donde los artesanos expresaban explícitamente su interés por temas electorales (Posada, 1996, p. 165; Uribe, 2003, pp. 92-98; Monsalvo, 2012), en Antioquia es difícil establecer de manera veraz la opinión de sectores 
populares sobre el sufragio, las elecciones y la representación política, aunque sí se pueden recoger apreciaciones de quienes decían expresar o reflejar una opinión "popular" sobre el tema. Los testimonios citados a continuación dejan dudas acerca de la condición social de sus autores, pero es de resaltar que el tema se debatió públicamente, aunque de manera tardía.

A propósito de las elecciones de 1844, se expresaron opiniones que cuestionaban el carácter elitista de los comicios y planteaban el involucramiento de sectores populares en la política electoral. En Guatapé, ubicado en el cantón de Marinilla, unas personas identificadas como "artesanos" publicaron una hoja suelta en la cual argumentaban que la justificación del Gobierno republicano eran las elecciones, unas "fiestas [...] chirriadas" en las que cada uno podía dar su voto por el candidato que le gustaba. Sin embargo, los denominados artesanos cuestionaban que la conformación de listas de electores la hicieran los "caballeros de la sangre azul i de la agalla verde", lo que no resultaba "justo". Con base en estos elementos, los firmantes de la hoja declararon que no eran "tan ovejos" como para votar por aquella lista, y propusieron una propia que, al parecer, fue cuestionada por algunos jefes políticos de Medellín (Otros artesanos, 1844).

Sobre otras apreciaciones, cabe dejar un interrogante abierto por el elitismo que traslucen. Un ejemplo es la publicación en la que se reproduce un diálogo ficticio ${ }^{1}$ entre dos personas del común, a propósito de la campaña electoral de aquel año, en el que se insinúa la presión de algunos sectores por involucrar, en el debate político electoral, al pueblo llano, diálogo que también puede evidenciar el desinterés de las élites por involucrar a aquel en la "follisca eleccionaria".

Mepica: ¿De qué clase de inflamación es que me hablas, Aguanta?

Aguanta: [...] esta mi inflamación la llama mi comadre Cruz, inflamación electoral, o cucañal, peste que anda recorriendo todo el estado, como el romadizo.

1 Este tipo de documentos, en los que aparentemente dialogan personas del común o expresan su opinión sobre temas políticos, son frecuentes en la época. Fueron publicados como hojas sueltas y es posible que hayan sido escritos por personas ilustradas que intentaban, por un lado, criticar algún tema específico de manera encubierta y, por otro, recoger opiniones corrientes sobre dichos temas. 
Mepica: [...] ¿con que tenemos ya a mi padre Adán metido en follisca eleccionaria? ¿No veis majadero que ni tus luces, ni tu males, ni tu mucha edad te hacen acreedor a empleos, que es lo que desean la mayor parte de los que toman a su cargo sacar el mandatario que más esperanza les promete en su colocación? Aguanta, déjate de esa empresa, ajena hasta ahora de tu carácter, i continua trabajando como hasta aquí para vivir con tu familia; no te metas en elecciones.

Aguanta: Mire U. que sermón acabo de oír aun antes de la misa, en altozano, i sin quitarme siquiera el sombrero: Mepica, contésteme esta pregunta: ¿Cuándo te ha dado calentura, te has metido en ella, o esta se ha metido en vos?

Mepica: Mi amigo, cuando he sido atacado por alguna fiebre, ella es la que se ha metido en mi, y no yo dentro de ella.

Aguanta: Pues así mismo me ha sucedido con las tales elecciones. Yo no me he metido en ellas, sino que quieren meterme (El Duende, 1844).

Durante la administración de Tomás Cipriano de Mosquera (1845-1849), algunos integrantes del Gobierno, como Florentino González, promovieron la organización artesanal, la cual se insertó en la agitación política y electoral (Colmenares, 2008; Gutiérrez, 1995; Sanders, 2004). En particular, los comicios presidenciales de 1848 marcaron un hito en la participación de sectores populares en las elecciones en Bogotá. ${ }^{2}$ A partir de entonces, la presencia de dichos sectores en los comicios fue frecuente, aunque no por ello menos proscrita y censurada por parte de dirigentes con una idea conservadora y republicana de la política.

Por ejemplo, en 1851, José Manuel Restrepo criticó fuertemente al gobierno de José Hilario López, porque, en conjunto con sus partidarios liberales, habían "conmovido por todas partes a las masas

2 Ninguno de los candidatos obtuvo mayoría proporcional, por lo que el Congreso decidió quién ocuparía la presidencia. Según comentaristas conservadores, en las sesiones hubo presencia de sectores populares, algunos con cuchillos en sus bolsillos, dispuestos a actuar en caso de que no fuera electo José Hilario López. De acuerdo a esta versión, después de un procedimiento irregular, confuso y desordenado por la acción de estos sectores, resultó electo López (Gómez, 1912, pp. 415-426). Según Fernán González (1997), esta fue "la primera vez en la historia política del país en que las masas populares intervinieron en la elección de un mandatario" (p. 116). 
ignorantes" (1954b, p. 120). Estas, en forma de clubs o sociedades democráticas, eran "la ley" y el Gobierno no tenía la "fuerza para contenerlos". Los comentarios de Restrepo (1954b, p. 120) sobre la agitación social y política eran seguidos por el registro del incremento de la delincuencia en el país, especialmente en Bogotá, como si una y otra se reforzaran recíprocamente (1954b, p. 120). En la provincia de Antioquia, la irrupción de sectores populares en la política electoral, al parecer, fue tímida, aunque desde 1851 se conformó una Sociedad Democrática en Medellín, liderada por Camilo Antonio Echeverri. Esta organización, aunque fue germen para discusiones ideológicas, disputó, sin mucho éxito, con la Iglesia y grandes propietarios, el control y subordinación de sectores populares (Arenas, 2003, pp. 206-207; Ortiz, 1991, pp. 119-120).

Así pues, parece que no hubo una notoria participación de sectores subordinados en la política electoral, pero en Antioquia, desde 1844, el asunto fue tema de discusión en algunos ámbitos públicos, en los que circulaban hojas sueltas que trataban el tema. Estos registros permiten intuir el problema del elitismo del sistema electoral, pero no es posible establecer si procedían de sectores populares o de ilustrados contestatarios que buscaran la participación de aquellos en la política formal. Esto resulta más evidente a principios del decenio de 1850, cuando tales ilustrados promovieron la organización de sociedades democráticas con el propósito de disputarle, sin mucho éxito, el control y capacidad de subordinación social a la Iglesia católica y a los grandes propietarios.

\section{Los sufragantes parroquiales y la falta de "hábitos republicanos"}

¿Quiénes eran las personas que estaban en el borde del círculo más restringido de la ciudadanía -como se lo representó Guerra-, es decir, quiénes eran los sufragantes parroquiales en Antioquia? ¿Qué proporción de la población total comprendían? Desde 1821, el sistema electoral restringió el derecho al voto a mayores de edad que contaran con propiedad, renta o profesión como garantes de independencia económica, criterios que fueron cambiando posteriormente, unas veces al eliminar requisitos (Constitución de 1832) y otras al incrementarlos (Constitución de 1842-43). 
Se ha establecido que la participación electoral en América Latina era "heterogénea", pero se ha concluido que, salvo excepciones como la de Brasil imperial, no más del $5 \%$ de la población se "involucraba en las votaciones" (Sabato, 1999, pp. 23-24). Para la historiografía colombiana, sigue siendo un interrogante el número exacto de sufragantes parroquiales que había en el país, en la primera mitad del siglo XIX. Se ha calculado que, en la época, la población de varones adultos que ejercía efectivamente el derecho al sufragio fluctuaba entre el $5 \%$ y el $10 \%$ de la población habilitada, una cifra superior, incluso, a la de algunos países europeos con mayores restricciones electorales. En todo caso, se ha advertido que la inasistencia a las elecciones desfiguraba la cifra de votantes potenciales. ${ }^{3}$

Sobre Antioquia, se ha dicho que la población con derecho a elegir era, probablemente, mayor que en el resto del país, aunque no se tiene claro qué proporción ejercía realmente este derecho (Melo, 1991, pp. 113-114). El estudio de los sufragantes parroquiales es tema para una investigación de gran alcance, pero es posible correlacionar algunos datos que dan idea de la cantidad de personas que ejercían el derecho al sufragio: censos de población y registros electorales. El mayor número de sufragantes estaba en los cantones de Medellín y Rionegro, los más densamente poblados de la provincia, probablemente los más prósperos y con mayor número de propietarios. En los demás cantones, con más baja densidad demográfica y, posiblemente, con menos propietarios avecindados, había un menor número de personas habilitadas para votar.

El número de sufragantes parroquiales en el cantón de Medellín fluctuaba, posiblemente por el interés variable que despertaban algunos comicios o por el alcance de la convocatoria que realizaban quienes aspiraban a ser electores de cantón. Un cálculo aproximado, considerando los votantes de 1831 (678) y el censo de 1835 (que registraba 21560 hombres), menos la población masculina que no tenía derecho al voto (11 712 esclavos, jóvenes y párvulos menores de 16 años), permite establecer que la cifra de sufragantes era, apro-

3 Ver David Bushnell (como se citó en González, 1997, p. 108). Con base en otros cálculos, se afirma que era el $7 \%$ o menos del $10 \%$ (Bushnell, 1998, p. 316). 
ximadamente, del 6,92 \% del total de la población habilitada para hacerlo (Archivo Histórico de Medellín [AHM], C, 1831, t. 112, ff. 137r-214r; 224r-229r; 231r-238r; 245r-247r). ${ }^{4}$

Estos datos son confirmados por testimonios según los cuales, en todo el país, las elecciones a las que asistían los sufragantes parroquiales despertaban poco entusiasmo, lo que para algunos ilustrados era un indicio de lo poco que se había avanzado en materia de participación política durante el régimen republicano. Según José Manuel Restrepo, las elecciones "primarias" eran muy importantes, pues en ellas se elegían los principales cargos políticos del país, pero era común que los "notables" no concurrieran a las votaciones, aunque duraran ocho días reglamentarios. A propósito de unos comicios en 1844, decía que, pese a todos los años de "ensayos sobre el gobierno republicano", aún no se concurría a las elecciones primarias, de las que dependían todas las demás, lo que era indicio de falta de "hábitos republicanos" entre los granadinos (Restrepo, 1954a, p. 384). La validez de estos testimonios debe verificarse, desde luego, con investigaciones más a profundidad sobre el voto primario.

Así pues, la puesta en práctica del sistema republicano provocó una apertura relativa de la política electoral en ámbitos locales. El sistema censitario e indirecto circunscribió la participación en la política formal a un reducido grupo de sufragantes parroquiales que, en el cantón de Medellín y posiblemente en el resto de Antioquia, no superaba el $7 \%$ de la población masculina, una cifra similar a la del país. Más allá de saber que se trataba de vecinos, casados o mayores de veintiún años, que contaban con una propiedad de \$100 o ejercían un oficio que garantizaba su "independencia" económica, es poco lo que se conoce de estas personas que estaban en la base del sistema electoral, lo que amerita la realización de investigaciones que exploren el tema a profundidad. La vía del ejército para ampliar el acceso al voto fue tema de debate a comienzos de los años veinte, pero se cerró desde 1827, cuando a sus integrantes se les exigieron los mismos requisitos de los sufragantes parroquiales.

4 Los datos de los votantes son incompletos, pues en algunas parroquias no se registró votación. 


\section{Los electores: el fundamento local del poder político}

Siguiendo el diseño institucional francés, el sistema político colombiano diferencia la parroquia del cantón, y al sufragante parroquial del elector. Tal como lo expuso François-Xavier Guerra (1999), en América Latina el cantón buscó "en vano [...] romper los comportamientos comunitarios" (p. 51). El elector, idealmente, representaba la posibilidad del voto independiente, calificado y libre con respecto a ataduras propias de las parroquias. En el sistema electoral colombiano indirecto, los electores elegían integrantes de la cámara provincial, el Congreso, diputados a congresos y asambleas constituyentes, así como al presidente y vicepresidente de la República, razón por la cual se convirtieron en actores clave del proceso político local, provincial y del país. ${ }^{5}$

Según la Constitución de 1821, cada parroquia, independiente del número de habitantes, realizaba una asamblea parroquial en la que los sufragantes votaban por los candidatos a electores establecidos por cada cantón: uno por cada cuatro mil habitantes y otro adicional por un residuo de tres mil habitantes; a partir de 1832, se amplió el número de electores, pues, por cada mil habitantes, se escogía un elector. ${ }^{6}$ Para ser elector, debían acreditarse más calidades que las de sufragante parroquial, aunque la Constitución de 1832 eliminó requisitos de propiedad o empleo, los cuales fueron restablecidos en la Carta Magna de 1842-43.

Existen datos más confiables sobre el número de electores que votaban en el país. Los aportados por Bushnell (1970) permiten advertir que, en la primera mitad del siglo XIX, hubo un incremento constante del número de electores de Antioquia en el país, pues pasó de representar el 3,7 \%, en 1825, al 9,5\%, en 1848. Este incremento,

5 El Artículo 34 de la Constitución de 1821 establecía que los electores de cantón tenían la función de elegir representantes, senadores, vicepresidente y presidente; la Ley del 11 de marzo de 1825 establecía que el 25 de diciembre de cada año los electores de cantón se reunían para elegir a los integrantes de la municipalidad (Gaceta de Colombia, 1826a).

6 Cada elector era escogido por cuatro años, pero en la práctica los lapsos no siempre fueron los establecidos. En caso de ausencia, la vacante era ocupada por la persona que le siguiera en número de votos (hay registros en los que aparecen "suplentes"). Ver Constituciones de 1821, 1832 y 1842-43 (Pombo y Guerra, 1986, p. 72). 
debido a la reducción del número de sufragantes para elegir un elector (1832), al crecimiento demográfico y al aumento de personas con calidades exigidas por la ley, permite concluir, preliminarmente, que la importancia electoral de la provincia creció en los primeros años de vida republicana.

Por otro lado, este incremento contribuyó también a aumentar el número de personas que ingresaban, por la vía electoral, al "mundo de la política" en cada cantón. No menos significativo es el hecho de que, a partir de los electores, áreas fronterizas hasta ese momento carentes de importancia y reconocimiento político fueron incorporadas al mapa político de la provincia. Marcela Ternavasio (1995) plantea, para el caso de Buenos Aires, que esa "ruralización de la política" muestra el paso de "un régimen notabiliar de base fundamentalmente urbana a un régimen de unanimidad de base urbano rural" (pp. 84-85), algo que sucede también en la Antioquia de la primera mitad del siglo XIX, al constatar el origen del apoyo a los electores designados con mayor frecuencia entre 1822 y 1844 ?

\section{Antiguos y nuevos intereses en la política electoral}

¿Quiénes eran los electores en Antioquia? A diferencia de cargos concejiles o de gobierno, que tenían numerosas responsabilidades, no aportaban salario a quienes los desempeñaban y a menudo los obligaban a abandonar actividades privadas, ${ }^{8}$ la condición de elector era apetecida porque de ella derivaba el poder de elegir integrantes de corporaciones públicas cantonales, provinciales y nacionales, y suponía pocos compromisos adicionales que no implicaban abandonar asuntos particulares, salvo cuando el elector era designado como diputado o congresista. La importancia del elector como mecanismo de representación individual se incrementó en la misma medida que

7 Esta conclusión se deriva de un análisis de las listas de electores entre 1822 y 1842, elaboradas con base en registros del AHA y que no se reproduce aquí por su extensión.

8 Para Deas (1993), estas razones explican "la abstención de los notables de la política municipal" (p. 211), afirmación que debe matizarse, pues se trataba de una "abstención" selectiva, ya que los "notables" participaban activamente en la política electoral local. 
decayó la del cabildo como instrumento de representación corporativa con influencia local. Como se apreciará, la condición de elector fue punto de partida para que integrantes de las élites locales confirmaran su poder social y económico, para que personas surgidas desde abajo tejieran redes, con el fin de iniciar carreras políticas, partiendo de la base del sistema, o para que abogados o sacerdotes ratificaran su influencia social e ideológica ejercida desde los años de gobierno colonial.

Las postulaciones a electores eran voluntarias, siempre y cuando cumplieran requisitos, aunque demostrar interés explícito por hacer parte de una lista de candidatos o autoproclamarse era mal visto. Los requisitos formales propiciaron la participación de personas no directamente relacionadas con la élite, pero una parte significativa de los elegidos era de las familias que controlaban los principales cargos políticos, desde comienzos del siglo XIX, o tenía vínculos económicos con ellas. El conservador Estanislao Gómez Barrientos (1912) decía que ser elector implicaba una prueba de confianza, "era apetecido [y] se le confería, por regla general, a los ciudadanos más visibles y recomendables por condiciones de honradez, capacidad e interés por la causa pública" (p. 109). Se puede decir, siguiendo a Annino (1995), que eran personas que aspiraban a que su influencia social tuviera correspondencia política (p. 15). Los electores eran, directa o indirectamente, expresión de poderes locales en la política del cantón, la provincia y el país.

Algunos electores presentaban rasgos coincidentes con el origen, trayectoria, poder e influencia del gamonal, un tipo descrito por los ensayistas liberales de mediados de siglo (Kastos, 1972, pp. 148-150; Samper, 1976; Deas, 1993). El perfil de algunos de los principales electores del cantón de Medellín, en el lapso de 1822 a 1842, permite notar la paulatina asociación del poder social y económico con el poder político local bajo el régimen republicano, la incorporación de sectores económicamente influyentes a la política electoral concebida por el sistema republicano y la gestación de trayectorias individuales desde el nivel básico del sistema. 


\section{La representación de mineros, comerciantes, concesionarios de caminos y empresarios colonizadores}

Tan importante como la frecuencia de las elecciones para reconocer la manera como se crea un "espacio público" que reconfigura antiguas tradiciones políticas es el interés por el estudio de quienes buscaban elegirse y reelegirse como electores en esos comicios, y la forma como aglutinaban intereses en una época en la que las alianzas eran fluidas y cambiantes, y no daban cuenta de la existencia de partidos cohesionados, tal como fueron conformándose después de la Guerra de los Supremos, ni de poderes centrales capaces de hacerlo. A partir del estudio de patrones en las votaciones, Frank Safford (2005) demostró que los resultados generales de las elecciones, hasta la década de 1850, evidencian la poca capacidad del presidente para incidir sobre las juntas electorales e influenciar los resultados de los comicios (pp. 293-297). Podría reconocerse, tal como lo registra Rossana Barragán (2005), en Bolivia, "una construcción territorial anclada en los poderes locales" (p. 95), a partir de redes que aglutinan representantes y funcionarios de pueblos y espacios territoriales para la elección de representantes y del presidente.

Como se indica en la Tabla 1, el doctor José María Uribe Restrepo (1790-1854) fue elector en siete ocasiones (AHM, C, t. 98, f. 146v; t. 108, f. 288r; t. 195, ff. 98-146v; ; Archivo Histórico de Antioquia [AHA], R, E, t. 2511, f. 300v). Nació en Envigado, y era hijo de María Josefa Restrepo Vélez y Miguel María Uribe Vélez, uno de los comerciantes introductores más importantes de la villa de Medellín y minero, casado en varias oportunidades con mujeres de las más importantes familias de la Antioquia colonial (Catalina Uribe Ruiz y Lorenza Lema Álvarez). Uribe Restrepo era abogado y se desempeñó como rector del Colegio de Antioquia en 1823 (designado por José Manuel Restrepo), y agente de la tesorería de crédito nacional en 1827. Fue opositor a las medidas adoptadas por el presidente Simón Bolívar cuando este reasumió la presidencia y, como otros integrantes de la élite antioqueña, fue conminado a pagar un impuesto (“comparto") forzoso por deslealtad al gobierno (Gaceta de Colombia, 1823; 1828b; 1830a). 
Tabla 1. Principales electores en el cantón de Medellín, 1822-1842

\begin{tabular}{|l|l|}
\hline \multicolumn{1}{|c|}{ Nombre } & \multicolumn{1}{|c|}{ Años votado como elector } \\
\hline Dr. José María Uribe Restrepo & $\begin{array}{l}1822,1825,1827,1829,1832,1836 \\
\text { y } 1842\end{array}$ \\
\hline Juan Santamaría Isaza & $1822,1825,1827,1829,1832$ y 1836 \\
\hline Pbro. Manuel Tirado Villa & $\begin{array}{l}1822,1825,1827,1832,1836 \text { y } \\
1842\end{array}$ \\
\hline Dr. Antonio Uribe Restrepo & $1822,1825,1827,1829$ y 1842 \\
\hline Tomás Muñoz Luján & $1825,1829,1832,1836$ y 1842 \\
\hline Dr. Estanislao Gómez B. & $1825,1829,1832$ y 1836 \\
\hline Pbro. Felipe Restrepo Granda & 1832,1836 y 1842 \\
\hline Pbro. Lucio Villa Tirado & 1829,1832 y 1836 \\
\hline Dr. Sinforiano Hernández & 1836 y 1842 \\
\hline
\end{tabular}

Fuente: elaboración propia con base en información del AHM y Bushnell (1970).

El poder económico lo derivaba Uribe Restrepo de su condición de propietario de minas y comerciante de oro en Anorí, San Pedro, Amalfi y Amagá, en donde fue copropietario de El Zancudo (comprada a Francisco Montoya), una de las más importantes en Antioquia, cuya producción empezó a hacerse notoria desde comienzos del decenio de 1840; esta mina fue heredada por su única hija, Lorenza Uribe Lema, casada con Carlos Coriolano Amador. Roger Brew (2000, p. 57) calcula que, en 1853, sus ingresos llegaron a $\$ 23000$, uno de los más altos en Antioquia y en el país en ese momento. Uribe fue promotor de la eliminación del impuesto a la producción y circulación del oro (el "quinto"), crítico permanente de la legislación de minas que resultaba gravosa en materia fiscal y defensor de la elaboración de un código que diera seguridad jurídica a las inversiones de los mineros (Botero, 2007, pp. 52-58; Molina y Castaño, 1987; Uribe, Moore, Vásquez y Echeverri, s. f.). 
La riqueza e influencia de Uribe Restrepo en Envigado, Medellín y otros lugares donde era propietario de minas y comerciante le sirvieron de punto de apoyo para su carrera política. Por ejemplo, en las votaciones para elector de 1832, obtuvo 51 votos en Medellín, donde estaba residenciado y tenía sus negocios; 30 en Envigado, donde había nacido y vivía parte de su extensa parentela; 18 en Belén; 14 en Amagá y 10 en Titiribí, zona de influencia de su mina El Zancudo (AHM, C, t. 114, ff. 221r; 243r-v; 248v; 264r; 271r-v). Además de la condición de elector en los años mencionados, fue diputado a la Cámara Provincial (1835 y 1840) y presidente de la misma (1840), así como gobernador de la provincia (mayo-agosto de 1841).

Su poder e influencia política local eran mucho más amplios, pues su hermano, Antonio Uribe Restrepo (1789-i?), también fue elector en cinco oportunidades (1822, 1825, 1827, 1829 y 1842) y diputado suplente por Antioquia al Congreso Constituyente de 1831; además, una hija de Antonio, María Josefa Uribe Ochoa, se casó con Sinforiano Hernández, quien fue elector en 1836 y 1842. Esta trayectoria y las relaciones familiares y políticas le sirvieron a José María para llegar al Congreso de la República, en donde se desempeñó como senador principal y suplente $(1835,1837,1840,1850)$, llevando la vocería de los mineros de Antioquia. Este defensor del libre comercio era, según Gómez Barrientos (1912), el "prototipo del buen conservador" (Restrepo, 1944).

Como se aprecia en la Tabla 1, otro frecuente elector fue Juan Santamaría Isaza (1780-1840), quien desempeñó tal función en seis oportunidades (AHM, C, t. 98, f. 146v; t. 104, f. 478r; t. 108, f. 288r; t. 195, f. 129v;). Santamaría era hijo del español Manuel Santamaría y de María Josefa Isaza. Era uno de los comerciantes más ricos de la provincia, cuya fortuna creció con los negocios que propició la República: pionero en la ruta de Jamaica después de declarada la Independencia e introductor de mercancías; especulador con bonos de deuda pública que expidió la República para financiarse y pagar a sus funcionarios y soldados; propietario de minas y fundador de la Sociedad de Minas de Antioquia; concesionario del camino público de Caramanta y promotor de la colonización empresarial en el suroeste de Antioquia. 
En torno a este elector se integró una red familiar, empresarial y política ampliamente extendida por esta zona, cuya frontera, paulatinamente, fue integrándose social, económica e institucionalmente. Los votos obtenidos en 1832 como elector procedían de Medellín (48), domicilio de sus compañías, y de Fredonia (10), uno de los lugares en el suroeste desde donde se concentró la estrategia colonizadora de la conocida Montaña de Caramanta (AHM, C, t. 114, ff. 221r-268v). Su hijo Santiago, su protegido Gabriel Echeverri Escobar, su socio Juan Uribe Mondragón y su amigo Pedro Antonio Restrepo Escovar fundaron los pueblos de Nueva Caramanta, Piedras (Jericó), La Soledad (Andes) y Valparaíso (Brew, 2000; Hincapié y Álvarez, 1998; Vélez, 2000).

La carrera política de Juan Santamaría fue menos destacada que la de Uribe Restrepo, pero su influencia en la provincia no era menor: integrantes de su núcleo familiar figuraron en la conspiración contra el presidente Bolívar en 1828, por lo cual fueron conminados a pagar impuestos forzosos por deslealtad al gobierno (Gaceta de Colombia, 1828a; 1828b; Gaceta de Colombia No. 453, 1830a). Además de elector, fue designado jefe político del cantón de Medellín en 1825, diputado a la Cámara provincial en 1835 y gobernador de la provincia por encargo (octubre de 1835-febrero de 1836). Los integrantes de esta red también fueron electores, principalmente votados en localidades del cantón, como Gabriel Echeverri, en 1836; Santiago Santamaría por Fredonia, en 1842; Juan Uribe Mondragón por Fredonia, en 1836; Cristóbal Uribe Mondragón por Fredonia, en 1836 y 1842; y Salvador Escobar por Titiribí, en 1836 y 1842 ( p. 3; AHA, R, E, t. 2511, f. 245r).

Estas redes, cuya influencia se extendía de Medellín a la zona territorial recientemente incorporada de manera formal, evitaron en Antioquia la segmentación política entre grupos con dominio urbano y otros de índole rural, tal como sucedió en otros países de América Latina, y que dieron lugar a "partidos" de ascendencia rural y a "partidos" de carácter más urbano. También es indudable que la condición de electores sirvió de plataforma política para apoyar aquellas empresas que requerían de respaldo gubernamental. Como introductores de mercancías, compartieron su defensa de medidas li- 
brecambistas y, desde finales del decenio del cuarenta, pertenecían a círculos de tendencia liberal en la provincia, aunque posteriormente se reagruparon políticamente en el conservatismo.

La situación descrita no era exclusiva del cantón de Medellín. Una muestra aleatoria permitió establecer que la condición de elector era deseable para los integrantes de las élites de otras capitales cantonales. Por ejemplo, en el año de 1836, resultaron electas personas como José María Martínez Pardo, Pablo Pardo, Víctor Pardo, Fernando Uruburu, Juan E. Martínez, Jorge Martínez, Manuel Martínez y Eugenio Martínez, todos relacionados y pertenecientes a una de las familias más poderosas de la ciudad de Antioquia: la Martínez Pardo. En Rionegro, se hicieron elegir Luis Lorenzana, Juan de Dios Aranzazu, Pedro Sáenz y Manuel Antonio Jaramillo, todos ellos vinculados directa o indirectamente con la familia Montoya o con los Córdova. En el cantón de Marinilla, resultaron electos los presbíteros Javier Gómez, Valerio Antonio Jiménez (que llegaría a ser obispo de la diócesis de Antioquia), Francisco Gómez, y los señores Miguel María Giraldo, Agustín y Gervasio Duque, y Pedro y Pío Quinto Gómez (Constitucional de Antioquia, 1836, p. 2).

Así pues, en la primera mitad del siglo XIX, grupos sociales y económicos tradicionales y emergentes, con un evidente interés en los espacios formales creados por el sistema republicano para acceder al poder político, empezaron a reafirmarse o consolidarse políticamente, desde la base del sistema electoral, construyendo redes que integraron intereses familiares, económicos y territoriales. En este contexto, se fue consolidando, en el mediano plazo, el tipo del "político comerciante", quien ascendió por medio de la política, los negocios con recursos públicos y su relación con el Estado; para Marco Palacios (2002), representa la que se considera "figura clave en el proceso político y en la formación del Estado nacional” (pp. 41-42).

\section{La relegitimación política de los sacerdotes}

El sistema republicano también abrió, formalmente, el "mundo de la política” electoral para los sacerdotes, quienes ejercían, de hecho, una importante influencia social e ideológica en la provincia. Según 
las normas, podían elegir y ser elegidos, algo que ocurrió, principalmente, a partir de 1830 .

Tal como se aprecia en la Tabla 1, el sacerdote Manuel Tirado Villa (hijo de José Antonio Tirado Álvarez y Ana María Villa Puerta) fue elector en seis períodos. El presbítero y doctor Lucio Villa Tirado (1773-1839) fue elector en tres oportunidades: 1829, 1832 y 1836. Villa era sobrino del también presbítero José Nicolás de Villa Molina y pertenecía a una familia propietaria de minas. Se formó en el Seminario de Santa Fe de Bogotá, y durante los años de la Independencia participó activamente en el bando patriota. Fue designado por Medellín a la Junta Provincial de Gobierno, reunida en la ciudad de Antioquia, en 1810. Asimismo, fue provisor de la diócesis episcopal, en 1813, y colaboró con el dictador patriota Juan del Corral. Se exilió, voluntariamente, cuando las fuerzas españolas iniciaron la reconquista de la provincia, y fue indultado en 1817 teniendo como testigo al gobernador José Vicente Sánchez Lima (Uribe Hincapié y Álvarez, 1998).

El presbítero Felipe Restrepo Granda (1787-1851), cura de Envigado, fue elector en 1832, 1836 y 1842. Era hermano medio del doctor José Félix de Restrepo, prohombre de la Independencia, y pertenecía a una familia modesta que contaba con recursos económicos para garantizar la educación de sus integrantes. Durante la Revolución de Independencia fue subdirector de la fábrica de pólvora en Antioquia que dirigió Francisco José de Caldas. Luego de enviudar en 1821 inició su carrera eclesiástica (1822) y, posteriormente, la política, en condición de elector. Su hijo, el doctor Pedro Antonio Restrepo Escovar, fue elector por Envigado, en 1842; secretario de la Cámara provincial, en 1843; diputado en la misma, en 1849, 1852, 1854 y 1855; representante por Antioquia al Congreso de la República, en 1844; y jefe político del cantón de Medellín, en 1847. Como congresista, Restrepo Escovar se opuso a la reforma político-administrativa propuesta por Mariano Ospina Rodríguez, a partir de la cual el país se subdividiría en 44 provincias. Su influencia política se extendió hacia el suroeste de la provincia, en donde era propietario de tierras, fundador del caserío de La Soledad (Andes), socio ocasional y amigo de los Santamaría. Al finalizar el decenio del cuarenta, hacía parte 
de los Amigos del País, grupo de liberales que publicaron hojas sueltas y periódicos para defender su proyecto y criticar a los jesuitas en Antioquia (Restrepo, 1992).

Aunque la mayoría de estos sacerdotes pertenecían a familias distinguidas de la provincia, algunos contaban con menos antecedentes sociales y económicos que les sirvieran para lograr reconocimiento político. Es notorio, al menos en los cantones de Medellín y Marinilla, el alto número de sacerdotes elegidos: Francisco de Paula Benítez (1792-1871), vicario de Medellín, elector en 1831, 1832, 1836 y 1842; Manuel Obeso (1792-1833), cura de Belén, elegido en 1831; el obispo Mariano Garnica (1779-1832), elegido en 1832; Pedro José Pérez Zea (1756-1847), cura de San Pedro y de Belén, elegido en 1836 y 1842; José Joaquín Escobar Arango (1775-1841), cura de Envigado, Amagá, Sabaletas y La Estrella, elegido en 1836; José Antonio Montoya de la Calle (1788-1865), cura de Amagá, Fredonia y Envigado, y Juan Nepomuceno Ruiz cura de lo que hoy se conoce como Heliconia, elegido en 1842.9

Hasta aquí se han mencionado electores que hacían parte de las élites políticas locales, otros que emergieron social y económicamente, y los que hacían parte de grupos tradicionales con poder social e ideológico que trataron de reafirmarlo con influencia política, a partir de 1821. De quienes figuraron casi consecutivamente como electores, se puede concluir que, además de los requisitos formales, tenían interés, recursos e "influencia", es decir, votos de sufragantes parroquiales para hacerse elegir y mantenerse en esa condición al menos durante dos decenios.

\section{La representación política: ¿privilegios, méritos, virtudes o riqueza?}

Los requisitos para ocupar un cargo de representación política fueron asunto de discusión permanente. Desde la Convención de Cúcuta, que dio origen a la Constitución de 1821, se debatió sobre las restricciones socioeconómicas del sufragio, prevaleciendo la idea de que al

9 Los datos biográficos fueron obtenidos de Piedrahita (1973, pp. 312-365). 
Congreso deberían asistir personas con propiedad, independiente de su vecindad o ilustración (González, 1997, p. 109). Pese a este acuerdo normativo, persistió el asunto de los méritos, virtudes, condiciones y riqueza que debían tener los aspirantes a "cargos de representación", tales como electores, diputados, representantes y senadores. En la prensa y oficios de los gobiernos central y provincial, las autoridades planteaban, a manera de una pedagogía cívica, un derrotero sobre las características de las personas que debían ser elegidas para garantizar la estabilidad y prosperidad de la República.

José Manuel Restrepo, secretario del Despacho del Interior, entre 1821 y 1830, planteó que el representante ideal para el republicanismo debía tener los siguientes rasgos: persona de juicio sano, corazón recto, íntegro, consagrado a sus deberes, amante del orden constitucional; de patriotismo, luces y probidad conocidos; capaz de desempeñar su cargo a satisfacción general y en favor del bien común; sabio, reflexivo, calmado, imparcial y moderado; apto para expresar pacíficamente su opinión, sostenerla y discutirla con libertad; que profesara amor al bien público, la patria, la humanidad, el orden y la justicia (Gaceta de Colombia, 1822a; 1825a; 1825d). Se estimaba que, con sujetos de estas características, se podían alejar del accionar político las pasiones, el espíritu faccioso y las rivalidades; las asambleas representativas quedarían a "cubierto contra la confusión, el tumulto y el espíritu de desorden y de partido"; asimismo, se evitaba que la ley concebida "en el combate de las pasiones celosas y turbulentas", perdiera la "moralidad" en que radicaba su fuerza (Gaceta de Colombia, 1825d). Esta aspiración republicana, valga la pena anotarlo, era contrariada por la práctica política cotidiana, por la creciente divergencia de los representantes y por la polarización de la prensa partidista.

En Antioquia, y seguramente en otras provincias de la República (Monsalvo, 2012), la condición socioeconómica seguía considerándose factor polémico para ocupar un cargo de representación política, no solo en lo establecido en la ley -como ya se expuso-, sino también en los discursos de quienes aspiraban a orientar la opinión. Un comentarista que publicó sus reflexiones en el Constitucional de Antioquia planteaba que las personas interesadas en ser elegidas debían ser patriotas, tener conocimientos y riqueza: 
Entiendo por patriotismo no el profesar estas ó aquellas opiniones, sino la disposición constante á hacer por el bien público todo lo posible; así un hombre aunque tenga las mejores ideas en política ó en lejislación si es perezoso i distraído, si tiene más afición á la quietud de sus lecturas i á sus gustos que á los negocios públicos será un mal representante. Respecto de conocimientos los que deben buscarse en los candidatos son los de la política, de la lejislación, de la economía política, de la ciencia administrativa i mui particularmente los de la jeografía i estadística de la Nuevagranada. En cuanto á la riqueza no pienso que el más rico sea el mejor lejislador; pero sí creo necesario que tenga todo diputado lo bastante para vivir con independencia. En el estado de atraso en que se halla entre nosotros la ilustración se hace difícil el encontrar bastantes individuos en quienes se reúnan en un grado notable estas circunstancias; i así es que si se encuentra un hombre animado del más puro i ardiente civismo carece de luces ó de fortuna, si es rico le falta el saber ó el patriotismo. De aquí resulta que con frecuencia es necesario atenernos á dos de las circunstancias solamente, siendo siempre una de ellas el patriotismo, porque sin este las luces i la fortuna no solo no pueden dar una garantía de buen proceder, sino que casi siempre son funestas al bien general (Constitucional de Antioquia, 1835, p. 1).

En la medida en que el tema se debatía localmente, se inscribía en las rivalidades y animosidades de la ciudad o la parroquia, y las opiniones se planteaban en relación con personas y circunstancias concretas. Es decir, al discutir los méritos y cualidades que debían tener los "representantes del pueblo", emergían antiguas rivalidades, viejos pleitos sobre honor y prestigio familiar, así como prejuicios contra sectores económicamente emergentes.

\section{Los pobres al infierno y los ricos a la cámara, al senado, a los ministerios y a la presidencia}

El debate público electoral que abordaba cuestiones relacionadas con los atributos de los aspirantes a cargos de representación electoral, a partir de 1836 reflejó la preocupación por el tema religioso, fiscal y educativo (Posada, 1996, pp. 167-169). En Antioquia, sin embargo, seguía teniendo un peso importante el perfil de los aspirantes 
a cargos de representación, concretamente sus antecedentes familiares, el origen de su riqueza y grado de ilustración. Una polémica, surgida en Medellín a comienzos de julio de 1835, puede ilustrarlo. Un artículo publicado en el Constitucional de Antioquia (1835) para "provocar" la discusión sobre candidatos a cargos de representación propuso una lista, en la que se incluían postulantes para dos plazas en la Cámara de Representantes: Gabriel Echeverri Escobar (principal) y Sinforiano Hernández (suplente), en la primera; Tomas Muñoz Luján (principal) y Antonio Mendoza (suplente), en la segunda.

La propuesta provocó una reacción inmediata, pues no había consenso sobre el perfil de los candidatos. En una hoja suelta se convenía en que la mayor parte de los aspirantes al Senado y a la Cámara provincial reunían "las calidades" requeridas para tales cargos, pero se denunciaba un "gato encerrado" en los nombres sugeridos como principales para la Cámara de Representantes, es decir, Muñoz y Echeverri. El desarrollo del debate hizo evidente el peso de antiguos parámetros para conceder reconocimiento político.

Tomás Muñoz Luján (1794-i?) era hijo de José Muñoz de Rojas Trujillo, alcalde pedáneo de Santa Rosa, a finales del siglo XVIII; comerciante y propietario de minas, y sobrino de Antonio Muñoz de Rojas Trujillo, alcalde segundo de Medellín, ambos comerciantes y propietarios de minas, pero no reconocidos socialmente por integrantes de la élite de Medellín; de hecho, Antonio sostuvo un largo pleito por la legitimidad y honor de su apellido. Los Muñoz hacían parte del grupo familiar de José María y Salvador Córdova Muñoz, de Rionegro, ocuparon cargos públicos e hicieron méritos políticos en el bando patriota durante la Revolución de Independencia. Tomás Muñoz Luján se convirtió en próspero minero y comerciante en el cantón de Santa Rosa, donde era propietario de minas de aluvión y veta. En 1817, Tomás fue indultado por las autoridades españolas y, posteriormente, designado por autoridades republicanas como regidor en el cabildo de Medellínen 1820 (Twinam, 1985, pp. 196-203; Uribe, 1985, pp. 214-215; Hincapié y Álvarez, 1998, pp. $425-$ 443). Además, Muñoz Luján fue elector en el cantón de Medellín en $1825,1829,1832,1836$ y 1842. 
En la campaña electoral de 1835, se impugnó el nombre de Muñoz Luján como aspirante principal por Antioquia a la Cámara de Representantes. En una hoja suelta fue calificado como "director de peones en la veta de la Trinidad", a diferencia de Mendoza, el suplente, de quien se destacaba su ilustración en política y legislación, su conocimiento y patriotismo, pese a que era "pobre". Refiriéndose a Muñoz, el libelo planteó que su riqueza ("tres millones [...] en Hamburgo i los seiscientos mil pesos en Bogotá") no podía ser el único mérito para alcanzar tal posición, pues se demeritaba la "buena moral" y la "ilustración". De prevalecer esta candidatura, se afirmaba que se impondría la siguiente consigna política: "fuera pues los pobres, adentro los ricos; los primeros al infierno i los segundos al senado, a la cámara de representantes, a los ministerios i hasta la presidencia" (Dos Electores, 1835). La defensa de Muñoz se expuso en una hoja suelta que decía que este ni era médico ni científico, pero argumentaba que el saber no dependía de un bonete y unas borlas; resaltaba su honradez, la adquisición legítima de su patrimonio, su "buen sentido" y "su aplicación asidua y [...] anhelo para instruirse" en las materias necesarias para el ejercicio político (Otro elector, 1835).

Un caso similar ocurrió con Gabriel Echeverri Escobar (17961886), nacido en un hogar humilde en Guacimal (entre Hatoviejo y Copacabana). Inicialmente, se dedicó a la agricultura y al comercio minoritario, pero acumuló fortuna y se convirtió en comerciante importador de Jamaica. Fue protegido de Juan Santamaría, casado con Francisca Bermúdez, hermana de María Josefa, esposa de Juan; socio de Santiago Santamaría en la concesión Echeverri, empresario colonizador, fundador de Caramanta, propietario de salinas y accionista de casas comerciales como Echeverri y Santamaría, y Echeverri, Llano y Cía. Fue regidor de Medellín e integrante de la Junta Curadora (1824), personero municipal (1827), jefe político del cantón de Medellín (1833), personero provincial (1834), elector (1836), y gobernador (1841 y 1844) (Llano, 1890; Brew, 2000; Vélez, 2000).

Cuando Echeverri Escobar aspiró al Congreso por Antioquia, en 1835, su nombre fue rechazado por los mismos sectores de la opinión local. Argumentaban que no podía ser un buen legislador, porque no 
había sido un buen síndico provincial; recordaban que fue acusado de defraudar la hacienda provincial por sus actividades (¿contrabando?) con el tabaco; reconocían que era rico, pero mencionaban de soslayo dudas sobre el origen de su riqueza, patriotismo y conocimiento. Compararon su nombre con el de Sinforiano Hernández, de quien decían que, aunque no era rico, tenía luces y patriotismo suficientes para ocupar el cargo. Concluían que la virtud elegía siempre "para su morada el corazón del hombre honrado i pobre [y huía del] opulento, avaro i criminal que no tiene por norte sino el acrecentamiento de su poder i su fortuna, ni más patria que aquella en que puede medrar con mayor facilidad" (Dos Electores, 1835).

Gabriel Echeverri y Tomás Muñoz, hombres ricos, pero sin formación profesional ni orígenes familiares notables, no resultaron electos para el Congreso, aunque ello no impidió que ambos ejercieran poder y ocuparan cargos públicos por designación en el gobierno provincial. El debate sobre estos personajes escondía un cuestionamiento a su procedencia y ponía en evidencia que, en Antioquia, en el decenio del treinta, todavía influían los criterios tradicionales de honor y prestigio propios del régimen colonial, para validar postulaciones en cargos de representación política modernos. Por el contrario, Sinforiano Hernández ${ }^{10}$ (1806-1874) y Antonio Mendoza ${ }^{11}$ (1803-1887), hombres "pobres", pero con for-

10 Nació en Barbosa y se graduó como doctor en medicina del Colegio de San Bartolomé, fue maestro en el colegio especializado para mujeres fundado en el decenio de los cincuenta y profesor de química en el Colegio de Antioquia. Estuvo en el grupo de conspiradores contra el presidente Simón Bolívar en septiembre de 1828; enjuiciado y expulsado del país, se escapó, junto con Mariano Ospina, ambos opositores al gobierno de Urdaneta. Hernández pudo desarrollar una notoria carrera política como elector por el cantón de Medellín en 1836 y 1842; diputado a la Cámara provincial, en 1835,1852 y 1863; jefe político de Medellín y gobernador por encargo, en 1846.

11 Bogotano, doctor en medicina y notario. Se residenció en Rionegro en 1827. Apoderado de la familia Aranzazu y acusado de favorecer los intereses de González, Salazar y Cía., en un pleito de tierras en el sur de la provincia. Amigo y protector de Mariano Ospina Rodríguez cuando se refugió en Antioquia a causa de la conspiración septembrina; adhirió al levantamiento de José María Córdova contra Bolívar. Su carrera política fue respaldada por Juan de Dios Aranzazu,; a diferencia de este, que pasó de ser santanderista a conservador, Mendoza fue santanderista, pero se inclinó al liberalismo. Elector por Rionegro (1836), diputado por el cantón de Rionegro a la Cámara provincial (1836, $1837,1849,1855$ y 1858$)$ y representante a la Cámara por Antioquia $(1832,1837,1840$, 1846 y 1848). Colaboró con Salvador Córdova en su levantamiento contra el gobierno en 1841, primer gobernador de la provincia de Córdoba, entre julio de 1851 y enero de 
mación académica en medicina y derecho, así como con buenas relaciones sociales, sí resultaron electos.

Este debate permite ilustrar la persistencia, en la política electoral republicana, de criterios coloniales, para evaluar méritos de quienes aspiraban a cargos de representación. La "apertura" de este espacio, aun para algunos ricos, era relativa a partir de cierto nivel, y la riqueza, en sí misma, no era garantía para ocupar estos altos cargos. Personas como Gabriel Echeverri o José Antonio Muñoz lograron relacionarse con la élite local de Medellín y Rionegro, pero fueron rechazados entre sectores de la opinión con una posición elitista sobre el ejercicio de la política; aunque fueron electores y ejercieron una importante influencia política local, no lograron una mayor legitimación política por la vía del sufragio; y, a finales del decenio del cuarenta, figuraron entre los integrantes del liberalismo antioqueño. Sin embargo, no puede concluirse que la riqueza no era un factor decisivo en la política electoral.

\section{A modo de síntesis}

El indirecto y restrictivo sistema electoral establecido en Colombia desde 1821 excluyó a grupos tradicionalmente subordinados, abrió tímidamente el espacio político formal a algunos sectores y permitió la relegitimación por la vía electoral de las élites locales. La condición de sufragante parroquial fue ejercida por un porcentaje bajo de los hombres habilitados como tales, apenas superior al del resto del país, que no pasaba del $10 \%$. Los electores -claves en el proceso electoral porque elegían diputados a la Cámara provincial, congresistas, delegados a convenciones constituyentes, vicepresidente y presidente de la República- se incrementaron en la provincia de Antioquia y, en consecuencia, aportaron al aumento de su peso electoral en el país, pues pasó de tener el 3,7 \% de electores, en 1825, al 9,5\%, en 1848 .

El incremento del número de electores abrió las oportunidades para que habitantes de los cantones ingresaran al mundo de

1854. Apoyó a José María Melo en 1854, fue indultado y posteriormente expulsado a Ambalema. Regresó a Antioquia en 1860. Presidente del Estado Soberano de Antioquia, fue destituido por Pascual Bravo. 
la política electoral, pero el poder político siguió en manos de los grupos familiares que durante años de gobierno colonial controlaron, por razones de estatus, nobleza y capacidad económica, los principales cargos en los cabildos de Antioquia, Rionegro y Medellín. A diferencia de los fundadores de esas familias, los miembros de la tercera y cuarta generación debieron movilizar sufragantes parroquiales para ser elegidos como electores, cargo desde el cual trazaron trayectorias políticas en la base del sistema y protegieron sus intereses en la minería, el comercio, las empresas agropecuarias y las concesiones de obras públicas.

El objetivo de estos personajes al hacerse designar como electores cuestiona, de paso, la idea según la cual el rechazo de cargos de gobierno local obedecía a una hipotética apatía por la política o que el deseo de hacer dinero mediante negocios particulares los hacía desinteresados con respecto a la política y el devenir nacional; por el contrario, este afán y la necesidad de proteger empresas mineras, comerciales y agropecuarias los obligó a situarse, estratégicamente, dentro de nuevas instancias locales de representación que brindaban mayor poder político que los antiguos cabildos. Algunos electores que se apuntalaron políticamente en estos cargos fueron conformando redes político-electorales, a partir de las cuales integraron grupos de interés y áreas rurales en el espacio político nacional.

Los debates sobre méritos para acceder a cargos de representación política ponen en evidencia la persistencia de antiguos parámetros de honor y estatus para otorgar reconocimiento político. La riqueza era un factor importante, pero no suficiente para obtener dicho reconocimiento, sobre todo entre élites que, al promediar el decenio del treinta, todavía actuaban con base en prejuicios y criterios elitistas propios del mundo colonial. No obstante, debe reconocerse que personas sin tradición en cargos públicos ni familias notables que los respaldaran participaron en la política electoral como sufragantes parroquiales y como electores, aunque es evidente -en el caso de estos últimos- que su interés o recursos para sostenerse como tales eran menores【 


\section{Referencias}

Annino, A. (1995). Introducción. En Historia de las elecciones en Iberoamérica, siglo XIX (pp. 7-18). Buenos Aires: FCE.

Arenas, S. (enero-junio, 2003). Representaciones y sociabilidades en Medellín, 1856-1885. Estudios Políticos, 22, 193-224.

Barragán, R. (2005). Los elegidos: en torno a la representación territorial y la reunión de los poderes en Bolivia entre 1825 y 1840. En M. Irurozqui (ed.), La mirada esquiva. Reflexiones históricas sobre la interacción del Estado y la ciudadanía en los Andes (Bolivia, Ecuador y Perú). Siglo XIX (pp. 93-123). Madrid: Consejo Superior de Investigaciones Científicas.

Botana, N. (1995). Comentarios finales. En A. Annino, Historia de las elecciones en Iberoamerica, siglo XIX (pp. 469-479). Buenos Aires: FCE.

Botero, M. (2007). La ruta del oro. Una economía exportadora. Antioquia, 1850-1890. Medellín: EAFIT.

Brew, R. (1984). Aspectos de la política en Antioquia, 1850-1856. Medellín: Faes.

Brew, R. (2000). El desarrollo económico de Antioquia desde la Independencia hasta 1920. Medellín: Universidad de Antioquia.

Bushnell, D. (1966). El régimen de Santander en la Gran Colombia. Bogotá: Tercer Mundo.

Bushnell, D. (1970). Elecciones presidenciales colombianas, 1825-1856. En M. Urrutia y M. Arrubla, Compendio de estadísticas históricas de Colombia (pp. 219-312). Bogotá: Universidad Nacional de Colombia.

Bushnell, D. (1998). Procesos electorales, siglos XIX y XX. En Á. Tirado (dir.), Nueva Historia de Colombia (Tomo VII) (pp. 313-341). Bogotá: Planeta.

Castaño, Y. (2008). De menores de edad a ciudadanos: los indígenas de Antioquia y otras zonas neogranadinas frente a los postulados libertarios de la primera república, 18101816. Anuario de Historia Regional y de Fronteras, 13(1), 47-57.

Colmenares, G. (2008). Partidos políticos y clases sociales (4. - ed.). Medellín: La Carreta.

Deas, M. (1993). Algunas notas sobre la historia del caciquismo. En Del poder y la gramática, y otros ensayos sobre historia, política y literatura colombianas (pp. 207-231). Bogotá: Tercer Mundo.

Dos Electores (28 de julio de 1835). Elecciones. Medellín: Imprenta de Manuel Antonio Balcázar.

El Duende (18 de junio de 1844). Revelación curiosa. Medellín: Imprenta de Manuel Antonio Balcázar. 
Escorcia, J. (1983). Sociedad y economía en el Valle del cauca, 1780-1854 (Tomo III). Bogotá: Banco Popular.

Gómez, E. (1912). Don Mariano Ospina y su época (Tomo I). Medellín: Imprenta Editorial.

González, F. (1997). Legislación y comportamientos electorales. En F. González, Para leer la política. Ensayos de historia política colombiana (Tomo 1) (pp. 95-164). Bogotá: Cinep.

Guerra, F.X. (1999). El soberano y su reino. Reflexiones sobre la génesis del ciudadano en América Latina. En H. Sabato (coord.), Ciudadanía política y formación de las naciones. Perspectivas históricas de América Latina (pp. 33-61). México: FCE/El Colegio de México.

Guerra, F.X. (2012). Política antigua y política moderna en las revoluciones hispánicas. En A. Lepempériè y D. G. Lomné (comp.), Figuras de la modernidad hispanoamericana, siglo XIX y XX (pp. 133-156). Bogotá: Universidad Externado de Colombia.

Gutiérrez, D. (2018). Soberana indiferencia. El discurso historiográfico frente al republicanismo popular colombiano. Anuario Colombiano de Historia Social y de la Cultura, 2(45), 119-147.

Gutiérrez, F. (1995). Curso y discurso del movimiento plebeyo, 1849-1854. Bogotá: El Áncora

Hincapié, M. T. y Álvarez, J. M. (1998). Raíces del poder regional: el caso antioqueño. Medellín: Universidad de Antioquia.

Irurozqui, M. (1996). Ebrios, vagos y analfabetos. El sufragio restringido en Bolivia, 18261952. Revista de Indias, LXV(208), 698-742.

Irurozqui, M. (2005). Introducción. En La mirada esquiva. Reflexiones históricas sobre la interacción del Estado y la ciudadanía en los Andes (Bolivia, Ecuador y Perú). Siglo XIX (pp. 13-40). Madrid: Consejo Superior de Investigaciones Científicas.

Kastos, E. (1972). Escritos escogidos. En Costumbres parroquiales en Antioquia (pp. 148-159). Bogotá: Biblioteca Banco Popular.

Llano, T. (1890). Biografía del señor Gabriel Echeverri. Bogotá: Casa Editorial de Medardo Rivas \& Cía.

Loaiza, G. (2011). Sociabilidad, religión y política en la definición de la nación. Colombia, 18201886. Bogotá: Universidad Externado de Colombia.

Lynch, J. (2006). Simón Bolívar. Barcelona: Crítica.

Melo, J. O. (1991). Progreso y guerras civiles entre 1829 y 1851. En Historia de Antioquia (pp. 101-116). Medellín: Suramericana de Seguros.

Molina, L. y Castaño, O. (1987). El "Burro de oro". Carlos Coriolano Amador, empresario antioqueño del siglo XIX. Boletín Cultural y Bibliográfico, 24(13), 3-27. 
Monsalvo, E. (2005). Entre leyes y votos. El derecho de sufragio en la Nueva Granada 18211857. Historia Caribe, 4(10), 123-134.

Monsalvo, E. (2011). Las elecciones en los centros urbanos y rurales de la provincia de Cartagena, 1830-1840. Historia y Sociedad, 21, 117-145.

Monsalvo, E. (2012). Las elecciones y los poderes locales. El caso de Santo Toribio (Cartagena) 1836. Historia Caribe, 7(21), 109-139.

Monsalvo, E. y Medina, M. (2017). El sufragio en el mundo rural de la provincia de Antioquia. Las elecciones al cabildo de Manizales en 1852. Historia y Memoria, 14, 61-96.

Ortiz, L. J. (1991). Antioquia bajo el federalismo. En J. O. Melo (coord.), Historia de Antioquia (pp. 117-126). Medellín: Suramericana de Seguros.

Ospina, M. y Marín, J. (2018). Ciudadanía y elecciones en la Nueva Granada. Las definiciones y su reglamentación. Historelo, 10(20), 100-133.

Otro elector (julio, 1835). Elecciones. Medellín: Imprenta de Manuel Antonio Balcázar.

Otros artesanos (26 de junio de 1844). Carta congratulatoria a los artesanos. Medellín: Imprenta Manuel Antonio Balcázar.

Palacios, M. (2002). La fragmentación regional de la clase dominante en Colombia: una perspectiva histórica. En La clase más ruidosa y otros ensayos sobre política e historia (pp. 19-58). Bogotá: Norma.

Patiño, B. (1994). Criminalidad, ley penal y estructura social en la Provincia de Antioquia, 17501820. Medellín: Idea.

Piedrahita, J. (1973). Historia eclesiástica de Antioquia. Colonia e Independencia, 1545-1828. Medellín: Granamérica.

Pombo, M. A. y Guerra, J. J. (1986). Constituciones de Colombia (Tomo III). Bogotá: Banco Popular.

Posada, E. (1996). Alternancia y república: elecciones en la Nueva Granada y Venezuela, 1835-1837. En H. Sabato (coord.), Ciudadanía política y formación de las naciones. Perspectivas históricas de América Latina (pp. 162-180). México: FCE/El Colegio de México.

Registraduría Nacional del Estado Civil (1988). Historia electoral colombiana. Bogotá.

Restrepo, J. (1944). Gobernadores de Antioquia (Tomo II). Bogotá: Imprenta Nacional.

Restrepo, J. (1992). Retratos de un patriarca antioqueño. Pedro Antonio Restrepo Escovar, 18151899. Bogotá: Banco de la República. 
Restrepo, J. M. (1954a). Diario Político y Militar (Tomo III). Bogotá: Imprenta Editorial.

Restrepo, J. M. (1954b). Diario Político y Militar (Tomo IV). Bogotá: Imprenta Editorial.

Sabato, H. (1999). Introducción. En Ciudadanía política y formación de las naciones. Perspectivas históricas de América Latina (pp. 11-29). México: FCE/El Colegio de México.

Safford, F. (1977). Aspectos sociales de la política en la Nueva Granada, 1825-1850. En Aspectos del siglo XIX en Colombia (pp. 153-199). Medellín: Hombre Nuevo Editores.

Safford, F. (2005). Desde la época prehispánica hasta 1875. En F. Safford y M. Palacios, Colombia: país fragmentado, sociedad dividida (pp. 15-446). Bogotá: Norma.

Salgado, E. (2014). Indios, ciudadanos y tributo en la Independencia neogranadina, Antioquia (1810-1816). Trashumante, 4, 26-43.

Samper, J. M. (1976). El triunvirato parroquial. En H. Luque, Narradores colombianos del siglo XIX (pp. xx-xx). Bogotá: Colcultura.

Sanders, J. (2004). A New Politics. En J. Sander, Contentious Republicans. Popular Politics, Race, and Class in Nineteenth Century Colombia (pp. 58-99). Durham: Duke University.

Ternavasio, M. (1995). Nuevo régimen representativo y expansión de la frontera política. Las elecciones en el Estado de Buenos Aires, 1820-1844. En: A. Annino, Historia de las elecciones en Iberoamérica, siglo XIX (pp. 65-105). Buenos Aires: FCE.

Twinam, A. (1985). Mineros, comerciantes y labradores: las raíces del espíritu empresarial en Antioquia: 1763-1810. Medellín: Faes.

Uribe, J. M., Moore, T., Vásquez, P., Echeverri, G. (s. f.). Contestación al artículo Código de Minas. Medellín: Imprenta de Manuel Antonio Balcázar.

Uribe, M. (1985). Geografía general del Estado de Antioquia en Colombia. Medellín: Autores Antioqueños.

Uribe, V. (2003). Sociabilidad política popular, abogados, guerra y bandidismo en Nueva Granada, 1830-1850. Respuestas subalternas y reacciones elitistas. Historia y Sociedad, 9, 89-116.

Vélez, J. (2000). Los pueblos allende el río Cauca. La formación del suroeste y la cohesión del espacio en Antioquia, 1830-1877. Medellín: Universidad de Antioquia. 


\section{Archivo}

Archivo Histórico de Antioquia (AHA), República, Eclesiástico, 1842, t. 2511.

Archivo Histórico de Medellín (AHM), Concejo, 1825, t. 98.

Archivo Histórico de Medellín (AHM), Concejo, 1827, t. 104.

Archivo Histórico de Medellín (AHM), Concejo, 1829, t. 108.

Archivo Histórico de Medellín (AHM), Concejo, 1831, t. 112.

Archivo Histórico de Medellín (AHM), Concejo, t. 114.

Archivo Histórico de Medellín (AHM), Concejo, t. 195.

\section{Periódicos y revistas}

Constitucional de Antioquia (1835). "Remitido". N. 134.

Constitucional de Antioquia (1836). "Discurso pronunciado por Miguel Uribe Restrepo”. N. 175.

Gaceta de Colombia (1822a). N. 32. "Circular a los Intendentes”, 26 de mayo de 1822, p. 1.

Gaceta de Colombia (1822b). N. 34. "Proclama", 9 de junio de 1822, p. 1.

Gaceta de Colombia (1823). N. 75. "Secretaría del Interior", 23 de marzo de 1823, p. 1.

Gaceta de Colombia (1824). N. 153. "Ley declarando que en el año de 1825 deben celebrarse las elecciones constitucionales". 19 de septiembre de 1824, p. 1.

Gaceta de Colombia (1825a). N. 174. "Circular a los Intendentes", 13 de febrero de 1825, p. 1.

Gaceta de Colombia (1825b). N. 177. “Otra a los Intendentes", 5 de marzo de 1825, p. 1.

Gaceta de Colombia (1825c). N. 194. "Ley. Imponiendo penas a los electores que no concurran a las asambleas provinciales ordinarias y estraordinarias", 3 de julio de 1825, p. 1.

Gaceta de Colombia (1825d). N. 201. "Sobre las próximas elecciones constitucionales", 21 de agosto de 1825 , p. 3 .

Gaceta de Colombia (1826a). N. 237. "Ley. Adicional a la del 11 de marzo de 1825 sobre gobierno político", 30 de abril de 1826, p. 1.

Gaceta de Colombia (1826b). N. 255. "Municipalidades", 3 de septiembre de 1826, p. 3.

Gaceta de Colombia (1827a). N. 310. "Lei. Reglamentando las elecciones de los diputados a la gran convención”, 23 de septiembre de 1827, p. 1.

Gaceta de Colombia (1827b). N. 311. "Cuadro estadístico de la república de Colombia", 30 de septiembre de 1827 , p. 4. 
Gaceta de Colombia (1828a). N. 346. "Donativo", 15 de mayo de 1828, p. 2.

Gaceta de Colombia (1828b). N. 390. "Donativo", 14 de diciembre de 1828, p. 3.

Gaceta de Colombia (1829a). N. 400. "Congreso Constituyente”, 15 de febrero de 1829, pp. 1-2.

Gaceta de Colombia (1829b). N. 401. "Congreso Constituyente”, 22 de febrero de 1829, pp-1-2.

Gaceta de Colombia (1830a). N. 453. "Provincia de Antioquia", 21 de febrero de 1830, p. 2.

Gaceta de Colombia (1830b). N.o 486, suplemento. "Departamento de Antioquia", 17 de octubre de 1830, p. 1.

Gaceta de Colombia (1831). N. 516. "otro. Reglamentando las elecciones de diputados para la convención nacional”, 15 de mayo de 1831, pp. 1-2. 